\title{
SEKOLAH DASAR KONTEMPORER DENGAN FLEKSIBILITAS DAN KONEKTIVITAS RUANG SEBAGAI STRATEGI DESAIN
}

\author{
Martha Paramitha Maeliva ${ }^{1)}$, Maria Veronica Gandha ${ }^{2)}$
}

1)Program Studi S1 Arsitektur, Fakultas Teknik, Universitas Tarumanagara, marthapmaeliva@gmail.com

2) Program Studi S1 Arsitektur, Fakultas Teknik, Universitas Tarumanagara, mariag@ft.untar.ac.id

\begin{abstract}
Abstrak
Teknologi Informasi dan Komunikasi telah menjadi bagian dari kehidupan generasi milenial, generasi Z dan Alpha. Dalam lingkungan pendidikan terbaru, makna "mengetahui" telah bergeser dari mampu mengingat dan mengulangi informasi menjadi mampu menemukan dan menggunakannya. Seharusnya di era dengan perkembangan teknologi yang begitu pesat, lingkungan pembelajaran yang terpusat pada siswa lebih bersifat konstruktivis dan fleksibel dan lebih sesuai untuk membangun pengetahuan para siswa. Untuk mempersiapkan siswa agar berhasil dalam perkembangan ekonomi pengetahuan, pembaharuan baru dalam sistem pendidikan dan lingkungan belajarnya diperlukan. Model pembelajaran dari segi kurikulum, kualitas ruang, konfigurasi ruang, dan program tersebut disesuaikan dengan perilaku mengajar guru milenial dan perilaku belajar murid generasi $Z$ dan Alpha sehingga menghasilkan lingkungan belajar yang kolaboratif antara generasi milenial sebagai tenaga didik dan generasi $Z$ dan Alpha sebagai peserta didik. Sekolah kontemporer dengan strategi desain yang memberikan fleksibilitas, konektivitas, kebebasan, ruang untuk interaksi sosial serta pendidikan peserta didiknya. Kurikulum dan program ruang yang mendekatkan pada program pendidikan dasar yang inovatif untuk bermain dan belajar di dalam dan luar ruangan dengan memperhatikan aspek perkembangan fisik, kognitif, emosional dan sosial anak. Sekolah Dasar Kontemporer adalah lembaga pendidikan formal yang bersifat wajib untuk anak usia 7-12 tahun dengan waktu tempuh 6 tahun yang mengintegrasikan metode pendidikan kontemporer dalam perspektif milenial, $Z$ dan Alpha.
\end{abstract}

Kata kunci: generasi; kontemporer; perancangan; perilaku; sekolah dasar

\begin{abstract}
Information and Communication Technology has always been part of the lives of millennials, generation $Z$ and Alpha, a significant difference in the learning process compared to previous generations. In the current educational environment, the meaning of "knowing" has shifted from being able to remember and repeat information to being able to find and use it. In an era with rapid technological development, student-centered learning environments are more constructivist and flexible and more suitable for building student's knowledge. To prepare students for success in the development of the knowledge economy, new developments in the education system and learning environment are needed. The learning model in terms of curriculum, room quality, space configuration, and the program is adapted to the millennial teachers teaching behavior and generation $Z$ and alpha students learning behavior so as to produce a collaborative learning environment between the millennial generation as teachers and generation $Z$ and alpha as students. Contemporary schools with design strategies that provide flexibility, connectivity, freedom, space for social interaction and the education of their students. Curiculum and space programs that provide innovative elementary learning programs for indoor and outdoor play and learning taking into account children's physical, cognitive, emotional and social developmental aspects. Contemporary Elementary School is a mandatory formal education institution for children aged 7-12 years with a 6 years term that integrates contemporary education methods in the perspective of millennial, $Z$ and Alpha.
\end{abstract}

Keywords: behaviour; contemporary; design; elementary school; generation 


\section{PENDAHULUAN}

Generasi milenial saat ini memiliki jumlah populasi terbesar secara global yang tengah berada di usia produktif. Di antara Generasi milenial yang sedang membangun karier adalah mereka yang kembali ke sekolah sebagai pendidik. Sebagian besar guru baru saat ini adalah Generasi milenial, serta generasi anak-anak sekolah saat ini, disebut Generasi alpha dan Generasi Z.

Teknologi Informasi dan Komunikasi (TIK) selalu menjadi bagian dari kehidupan generasi milenial, $\mathbf{Z}$ dan alpha, perbedaan nyata dalam lingkungan pembelajaran generasi milenial, $Z$ dan Alpha dengan generasi sebelumnya. Integrasi teknologi dalam kehidupan generasi tersebut mempengaruhi sikap, perilaku, serta mengubah cara otak siswa dan dunia bekerja, untuk menghadapi perubahan ini guru milenial perlu berpikir kritis dan kreatif untuk mengubah metode pengajaran dan membangun lingkungan pembelajaran fleksibel yang berpusat pada siswa. Lingkungan belajar yang fleksibel memberikan siswa kemandirian, kontrol, dan kepercayaan untuk mengendalikan pembelajaran mereka sendiri. Para siswa membutuhkan fleksibilitas untuk berkolaborasi, berinovasi dan berpikir kreatif dalam menyelesaikan masalah.

Lingkungan belajar dan sistem pendidikan di Indonesia masih banyak yang menggunakan sistem 'Teacher-Centered Learning'. Seharusnya di era dengan perkembangan teknologi yang begitu pesat, lingkungan pembelajaran 'Student Centered Learning' yang konstruktivis dan fleksibel lebih sesuai untuk membangun pengetahuan para siswa. Dibutuhkan pembaharuan sistem pendidikan konvensional agar dapat beradaptasi dengan karakteristik mengajar guru milenial dan perilaku belajar generasi $Z$ dan Alpha. Lingkungan belajar dan ruang belajar perlu gagasan baru untuk memfasilitasi cara belajar peserta didik.

Pendidikan dasar di sekolah (1-6 SD) menjadi titik yang paling signifikan untuk memberikan dasar pengetahuan, sikap dan keterampilan bagi anak. Berdasarkan hasil penelitian, sekitar $50 \%$ kapabilitas kecerdasan orang dewasa telah terjadi ketika anak berumur 4 tahun, $80 \%$ telah terjadi perkembangan yang pesat tentang jaringan otak ketika anak berumur 8 tahun dan mencapai puncaknya ketika anak berumur 18 tahun, dan setelah itu walaupun dilakukan perbaikan nutrisi tidak akan berpengaruh terhadap perkembangan kognitif (Gandha, 2015). Jadi, selain anak banyak menghabiskan waktunya di sekolah, kapabilitas kecerdasan orang dewasa berkembang pesat pada usia 6-12 tahun. Menurut data Kementrian Pendidikan dan Kebudayaan (2016), angka partisipasi sekolah dasar merupakan yang paling tinggi dengan APK 106,44\% dan APM 93,73\% dibanding jenjang lainnya.

Sekarang, untuk mempersiapkan siswa agar berhasil dalam ekonomi pengetahuan, model sekolah kontemporer lebih mudah dipahami untuk memberikan fleksibilitas, konektivitas, dan ruang untuk pertemuan sosial dan pendidikan. Sekolah dasar dengan pendekatan kontemporer dari segi pendidikan maupun perancangannya diharapkan dapat meningkatkan aspek perkembangan fisik, kognitif, emosional dan sosial anak dalam proses pembelajarannya melalui ruang belajar yang interaktif dan fleksibel.

Sekolah Dasar Kontemporer adalah lembaga pendidikan formal yang bersifat dengan sasaran penggunanya ditujukan untuk anak-anak yang memasuki jenjang pendidikan sekolah dasar (7-12 tahun) dengan waktu tempuh 6 tahun yang mengintegrasikan metode pendidikan kontemporer dalam perspektif peserta didiknya. Sistem pendidikan yang disesuaikan dengan karakteristik guru milenial dan perilaku belajar generasi $Z$ dan Alpha tersebut mampu menghasilkan tipologi sekolah dan ruang pembelajaran yang berbeda dari sekolah dengan sistem pendidikan konvensional.

\section{KAJIAN LITERATUR}

Teknologi informasi dan pengetahuan tumbuh dengan laju yang jauh lebih cepat daripada sebelumnya dalam sejarah umat manusia. Teknologi mengubah cara hidup, bekerja, bermain, 
dan berpikir. Makna "mengetahui" telah bergeser dari mampu mengingat dan mengulangi informasi menjadi mampu menemukan dan menggunakannya (Simon, 1996).

Pendidikan terbaru tidak hanya tentang transfer informasi berbasis fakta dan pendidikan perlu lebih banyak tentang mengeksplorasi dan membangun keterampilan siswa untuk berkembang di masa depan. Menurut survei forum ekonomi dunia pada tahun 2016 tentang Masa Depan Pekerjaan di tahun 2020, "berbagai pekerjaan akan membutuhkan tingkat kemampuan kognitif yang lebih tinggi seperti kreativitas, penalaran logis dan sensitivitas masalah yang sebagai bagian dari rangkaian keterampilan inti mereka." Sehingga pendidikan terbaru harus memberikan penekanan khusus pada pengembangan pemikiran kritis dan keterampilan memecahkan masalah, sehingga siswa mampu untuk melihat masalah dari sudut yang berbeda dan merumuskan solusi mereka sendiri.

Pendidikan harus beradaptasi dengan Revolusi Industri Keempat untuk memastikan hasil terbaik bagi generasi anak sekolah saat ini, yaitu generasi Z dan Alpha. Sebuah studi yang dilakukan oleh Barnes dan Noble College menunjukkan bahwa siswa saat ini menolak untuk menjadi pembelajar pasif. Pembelajaran pendengaran, seperti ceramah dan diskusi, sangat tidak disukai oleh kelompok ini, sedangkan pembelajaran aktif yang melibatkan mereka dalam proses belajarnya seperti permainan interaktif, proyek kolaborasi, penyelenggara tingkat lanjut, dan tantangan, dihargai (Rothman, 2016).

Generasi milenial adalah generasi pertama yang tumbuh sepenuhnya dalam teknologi informasi. Sebagai penduduk asli digital, guru milenial terbiasa terlibat dengan beragam bentuk konten pada berbagai platform. Guru milenial melakukan perubahan pada metode pengajaran tradisional dan mengadaptasikan lingkungan pembelajarannya dengan kebutuhan dan preferensi generasi $Z$ dan alpha sebagai peserta didik. Guru milenial mendukung pembelajaran yang berpusat pada siswa karena lebih konstruktivis dan fleksibel dan sesuai untuk membangun pengetahuan para siswa serta meningkatkan kemampuan untuk menunjukkan penguasaan, pilihan pembelajaran sosial dan peluang kolaborasi.

Knowles (1975) memperkenalkan konsep pembelajaran mandiri yang didasarkan pada prinsip bahwa orang yang mengambil inisiatif dalam belajar akan belajar lebih banyak, termotivasi untuk belajar, mempertahankan dan memanfaatkan pembelajaran. Teori di balik belajar mandiri berasal dari kata andragogy. Andragogy adalah seni dan ilmu untuk membantu orang dewasa belajar (Knowles, Holton \& Swanson, 1998).

Prinsip Andragogy yang dianut Knowles adalah bahwa orang dewasa perlu dilibatkan dalam perencanaan dan evaluasi pengajaran peserta didik.

a. Self-Concept: Peserta didik ingin bertanggung jawab atas pembelajaran mereka sendiri. Menekankan pada individualisasi pengajaran dan pembelajaran karena itu akan memastikan kontrol penuh dari apa yang diinginkan peserta didik untuk diri mereka sendiri.

b. Adult Learner Experience: Orang dewasa belajar dari rekannya dan berbagai macam pengalaman dalam hidupnya. Milenial memilih lingkungan yang lebih inklusif, menghargai kontribusi kelompok dan menyediakan pembelajaran kuat antar teman untuk peserta didiknya. Metode belajar yang cocok adalah permainan, pembelajaran studi kasus yang melibatkan tingkat keterlibatan teman sebaya yang tinggi, pembelajaran aktif.

c. Readiness to Learn: Orang dewasa lebih suka belajar di mana penerapan pembelajaran terlihat dalam waktu dekat. Kepuasan instan.

d. Orientation to Learning: Orang dewasa adalah pelajar situasional dan belajar bergeser dari berpusat pada subjek (teori) ke berpusat pada masalah (praktis). Mereka akan belajar lebih efektif jika pengetahuan baru itu berlaku untuk situasi kehidupan nyata. Mereka perlu menghubungkan alat pembelajaran pengalaman dan situasi praktis.

e. Motivation to Learn: Pembelajar dewasa didorong oleh motivasi intrinsik seperti peningkatan kepuasan, kualitas hidup yang lebih baik. 


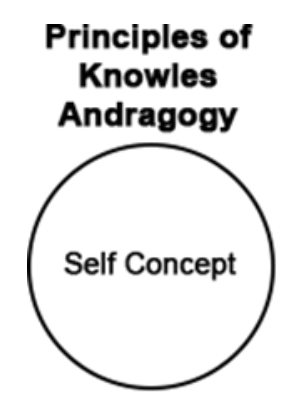

Tabel 1. Learning Model of Generation Collaboration

Millennials
Teaching
Methods
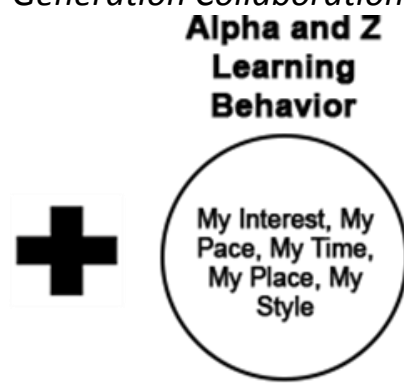

Effective
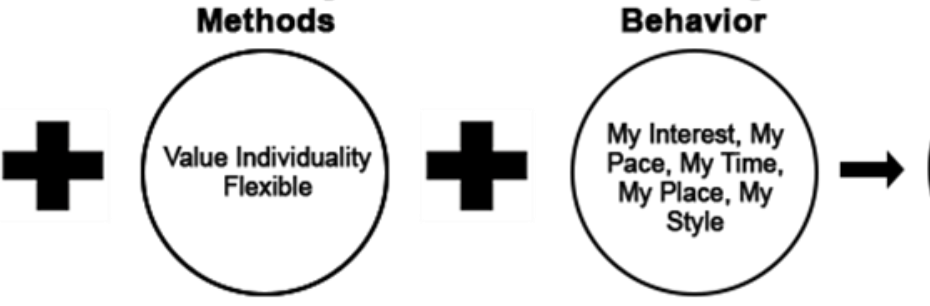

Learning

Methods
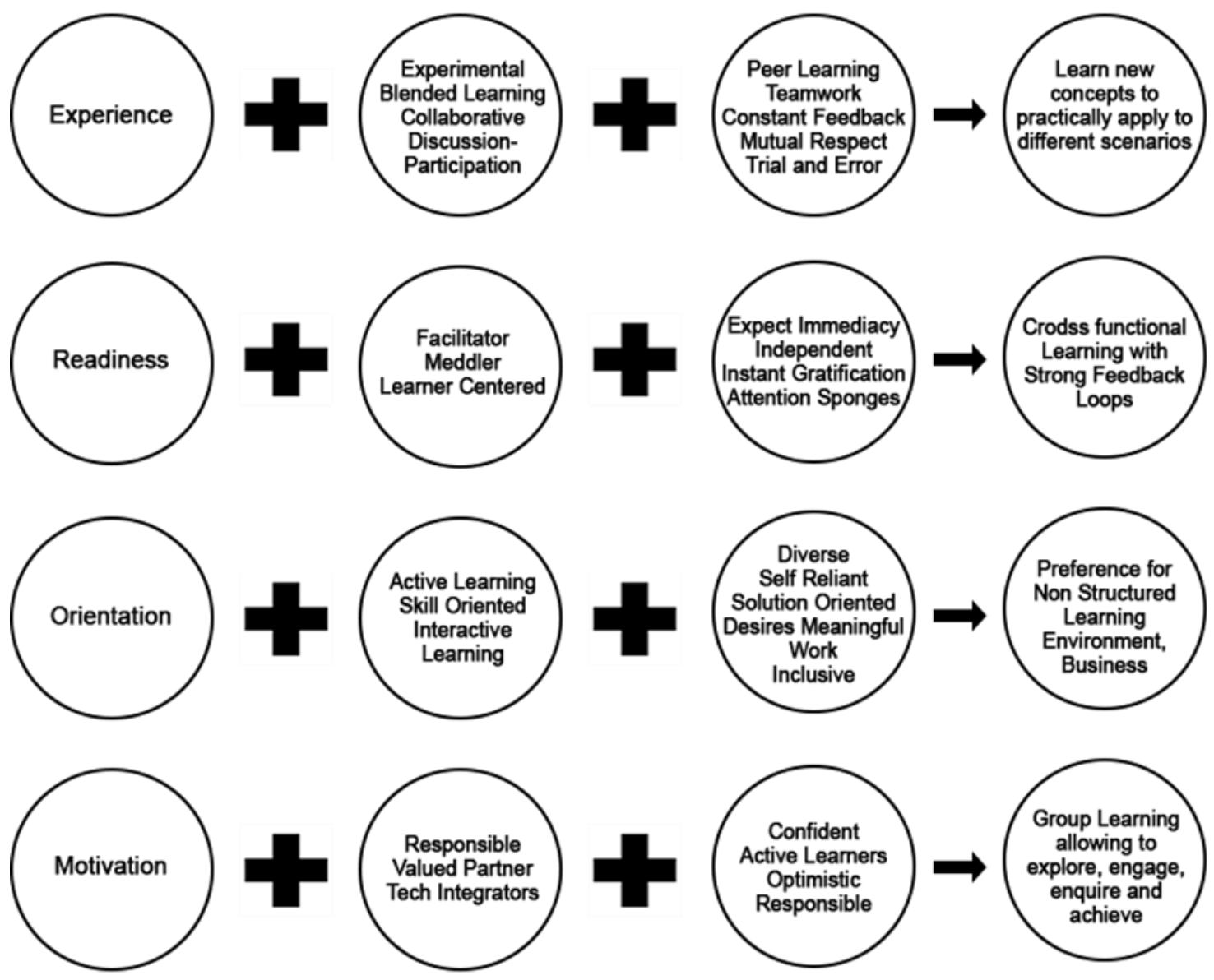

Tools \& Techniques
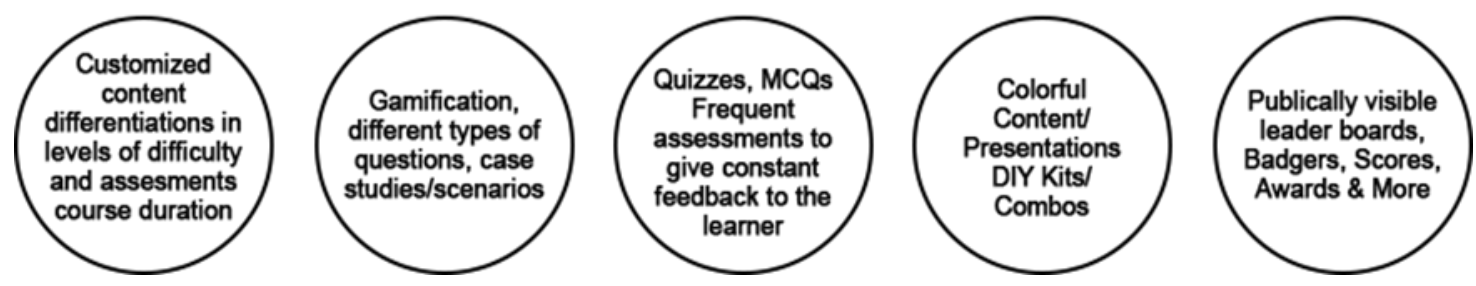

Sumber : Dokumen Pribadi, 2019

Mengintegrasikan pembelajaran Knowles Andragogy dengan mempertimbangkan perilaku dan kebutuhan generasi milenial sebagai tenaga didik dengan generasi Z dan Alpha sebagai peserta didik. Metodologi pembelajaran yang diadopsi oleh generasi milenial tersebut perlu diadaptasi agar lebih sesuai dengan generasi $Z$ dan Alpha. Peran guru sebagai fasilitator dan rekan belajar yang berdampingan dengan siswa dalam proses eksplorasi pengetahuan mereka. 


\section{METODE}

Metodologi yang digunakan adalah metode deskriptif, dengan pengumpulan data primer melalui observasi dan riset lapangan serta pengumpulan data sekunder berupa pustaka dan studi komparasi objek sejenis. Hasil dari keseluruhan analisis dan sintesa data dirumuskan untuk mendapatkan kesimpulan mengenai proyek yang bersangkutan.

Metodologi yang digunakan dalam perancangan sekolah adalah Pedagogical Space Design Method oleh Dimitri Germanos. Pedagogi mengacu pada interaksi diantara guru dan murid serta lingkungan belajar dan tugasnya. Metode perancangan ruang sekolah merupakan metode yang berdasarkan kombinasi kriteria pendidikan, arsitektur, dan psikologis. Pedagogical Space Design Method (Dimitris, 2016) , yaitu :

\section{a. The Creation of A Space Rich of Stimuli}

Sebuah ruang harus menawarkan berbagai rangsangan, visual, taktual, audio, dan kinestetik untuk meningkatkan sensitivitas anak. Mengintegrasikan lingkungan sekolah dengan proses belajar. Ruang untuk pengembangan aktivitas dan spontan yang dilakukan anak itu sendiri.

b. The Formation of Micro Environments

Mendukung pengembangan aspek pedagogi dan psikologis dari proses kerja sama. Memodifikasi organisasi ruang. Fleksibilitas ruang untuk aktivitas yang beragam.

c. The Creation of Educational Spaces

Menciptakan tempat-tempat edukasi dalam ruang. Anak-anak bebas untuk campur tangan langsung di ruang sekitarnya dan untuk menyesuaikannya dengan minat mereka sendiri.

\section{PEDAGOGICAL SPACE DESIGN METHOD}
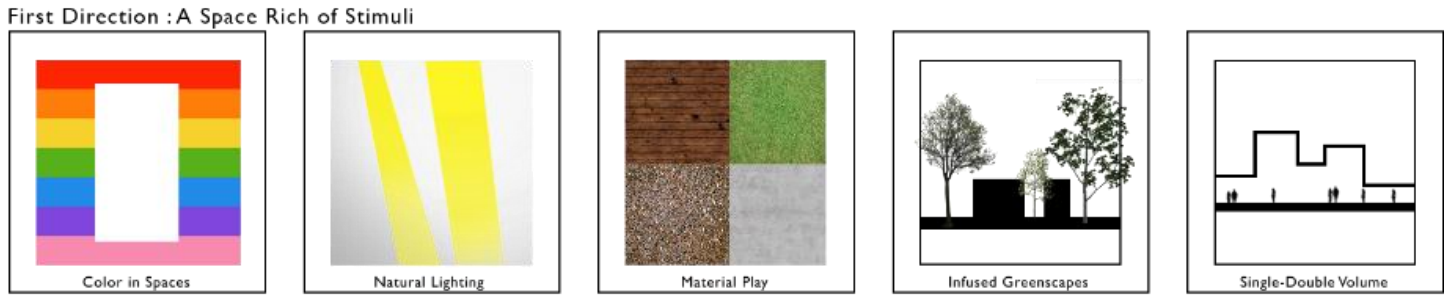

Second Direction : The Formation of Micro Environments
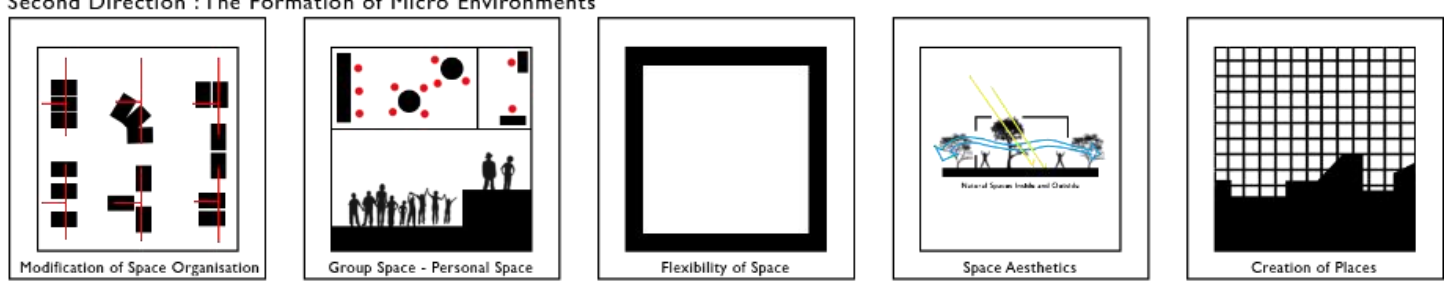

Third Direction : The Creation of Educational Places
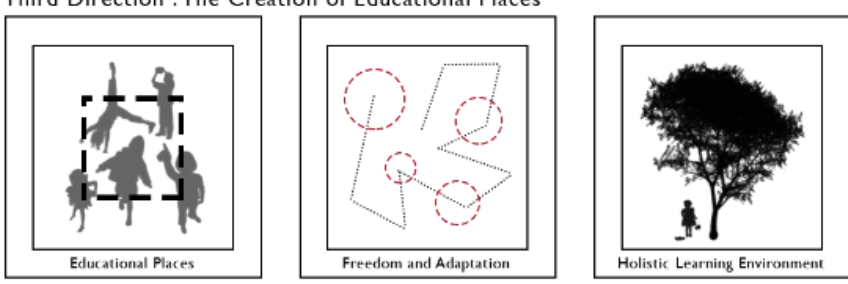

Germanos, Dimitri. 2016. "The PSD Method :

Pedagogical Space Design”. Greece: Aristotle University of Thessaloniki.

Gambar 1. Metode Perancangan

Sumber: Dokumen Pribadi, 2019

Aspek perkembangan anak menjadi pedoman dalam perancangan program sekolah dasar ini. Terdapat 3 aspek perkembangan anak, yaitu: aspek fisik/psikomotorik, kognitif, dan sosial/emosional (Knight et al, 2006). Aspek perkembangan anak yang diterapkan dalam perancangan arsitektir berupa (Gandha, 2015) :

a. Aspek Kognitif

Perkembangan kognitif dapat diterapkan dengan 3 cara, yaitu direct (pengamatan 
langsung dan keterlibatan langsung), indirect (pengamatan langsung namun tidak terlibat), serta simbol-simbol (objek pengamatan diwakili oleh hal-hal tertentu, seperti film, gambar, dII).

\section{b. Aspek Fisik}

Aktivitas dinamis dan interaksi dengan alam memacu penyaluran energi anak ke aktivitasaktivitas yang lebih sehat sehingga membantu perkembangan fisik yang lebih optimal.

\section{c. Aspek Sosial-Emosional}

Anak usia 8-11 cenderung tertarik untuk mengeksplorasi ruang luar di sekitar zona nyamannya. Pembelajaran di ruang bersama yang mendukung interaksi sosial dapat mengembangkan sosial-emosional anak. Ruang luar berupa alam menginspirasi anak untuk merasakan kebahagiaan, keceriaan, dan rasa ingin tahu.

Aspek perkembangan anak dan perkembangan indera juga diterapkan ke seluruh aspek ruang dengan variasi aktivitas. Kapasitas siswa yang akan ditampung pada Sekolah Dasar Kontemporer ini disesuaikan pada preseden yang ada. Jumlah ideal kapasitas siswa per kelas adalah 17-20 siswa dengan satu hingga dua rombongan belajar (kelas) setiap jenjang kelasnya.

$$
\text { Jumlah siswa }=20 \times 2 \times 6 \text { kelas }=240
$$

Jumlah pengajar pada Sekolah Dasar Kontemporer didasarkan pada kurikulum, alokasi waktu, dan jumlah jam pelajaran yang diterapkan sesuai dengan preseden. Perhitungan jumlah guru, sebagai berikut :

Tabel 2. Kebutuhan Tenaga Didik

\begin{tabular}{|c|c|c|c|c|c|c|c|c|}
\hline \multirow[b]{2}{*}{ Mata Pelajaran } & \multicolumn{6}{|c|}{ Alokasi Waktu } & \multirow{2}{*}{$\begin{array}{c}\text { Jumlah Jam } \\
\text { per Mata } \\
\text { Pelajaran }\end{array}$} & \multirow[b]{2}{*}{ Jumlah Pengajar } \\
\hline & I & II & III & IV & v & VI & & \\
\hline Pend. Agama & 2 & 2 & 2 & 3 & 3 & 3 & 18 & 3 \\
\hline $\begin{array}{c}\text { Ilmu Pengetahuan } \\
\text { Sosial }\end{array}$ & \multirow{7}{*}{\multicolumn{3}{|c|}{$\begin{array}{l}\text { Integrated } \\
\text { (tematik) ( } 2 \\
\text { tenaga pengajar } \\
\text { setiap kelas, } \\
\text { total } 6 \text { pengajar }\end{array}$}} & 4 & 4 & 4 & 12 & 2 \\
\hline $\begin{array}{c}\text { Ilmu Pengetahuan } \\
\text { Alam }\end{array}$ & & & & 2 & 3 & 3 & 12 & 2 \\
\hline Kewarganegaraan & & & & 3 & 3 & 3 & 9 & 2 \\
\hline Bahasa & & & & 5 & 5 & 5 & 15 & 3 \\
\hline Matematika & & & & 5 & 5 & 5 & 15 & 3 \\
\hline Teknologi Informasi & & & & 2 & 2 & 2 & 12 & 2 \\
\hline Kesenian & & & & 4 & 4 & 4 & 12 & 2 \\
\hline Peng. Jasmani & 2 & 2 & 2 & 4 & 4 & 4 & 18 & 3 \\
\hline Agrobisnis & 2 & 2 & 2 & 2 & 2 & 2 & 12 & 2 \\
\hline & & Tot & al Pen & gajar & & & & 24 \\
\hline
\end{tabular}

Sumber : Rofida, 2011

\section{DISKUSI DAN HASIL}

Sekolah dasar kontemporer merupakan wadah untuk kolaborasi antara generasi milenial sebagai tenaga didik dan generasi $Z$ dan Alpha sebagai peserta didik dalam menempuh pendidikan. Sekolah kontemporer dengan strategi desain yang memberikan fleksibilitas, konektivitas, kebebasan, ruang untuk pertemuan sosial serta pendidikan peserta didik dan pembimbingnya. 


\section{DESIGN SCHEME - STUDI MASSA}
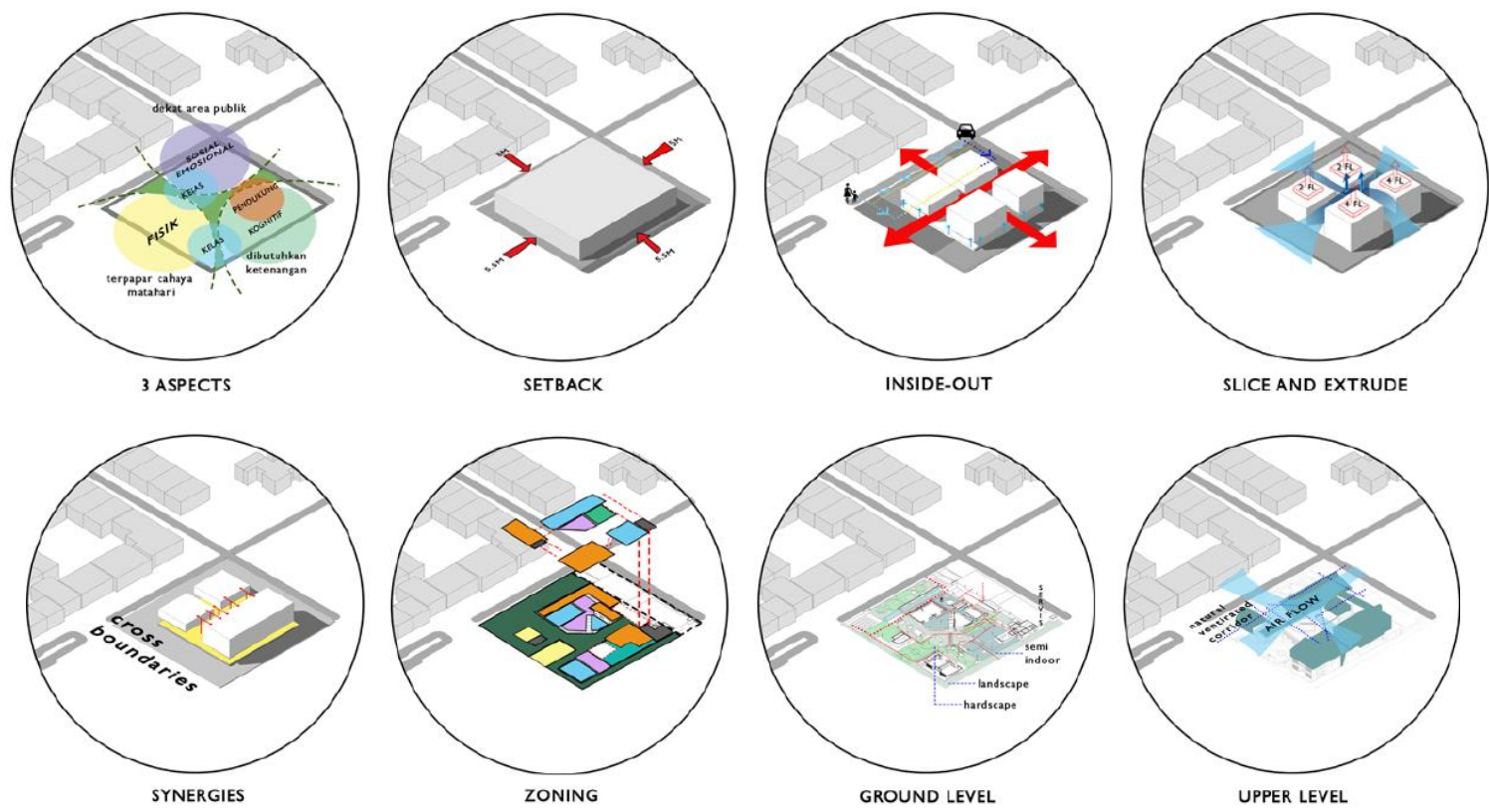

Gambar 2. Skematik Desain

Sumber : Penulis, 2019

Tahapan proses gubahan massa :

a. Tiga aspek perkembangan anak yang diintegrasikan dalam bangunan dan dibagi menjadi tiga zonasi pada lantai dasar. Ruang terbuka dan ruang hijau ditempatkan di antara tiga fungsi utama tersebut. Massa disesuaikan dengan kebutuhan zonasi.

b. Penyesuaian GSB untuk area yang dapat dibangun berdasarkan peraturan pemerintah.

c. Ketinggian bangunan disesuaikan dengan lingkungan sekitar. Pembelahan massa di tengah untuk area hijau terbuka dan memaksimalkan ventilasi alami pada koridor. Serta untuk kontak visual yang baik antar lantai.

d. Lantai dasar dibuat lebih terbuka dan tidak dibatasi banyak dinding melainkan terdapat banyak akses yang variatif dalam tapak, sehingga memungkinkan anak lebih bebas untuk bergerak dan bereksplorasi.

e. Lantai satu diletakkan ruang kelas 1 dan 2 untuk keamanan dan pengawasan yang lebih tinggi. Ruang administrasi, ruang guru, dan ruang kepala sekolah dikelompokkan para area depan. Fasilitas penunjang diletakkan lebih tersebar dalam tapak dengan aula utama diletakkan di lantai tiga.

f. Sirkulasi vertikal dibuat dengan ramp untuk mendukung desain yang aktif.

g. Lantai dua bersifat lebih fungsional untuk ruang kelas tiga sampai enam. Penggunaan koridor ditiadakan, sehingga menciptakan ruang belajar bersama (komunal) yang lebih besar untuk interaksi antar anak dan guru.

h. Ruang kelas dengan tipe kelas open plan yang memiliki kriteria rasio 3-5m2/siswa. Ruang kelas dilengkapi dengan furnitur yang mudah dipindahkan dan dikonfigurasikan untuk menyesuaikan dengan kegiatan dalam ruang. 


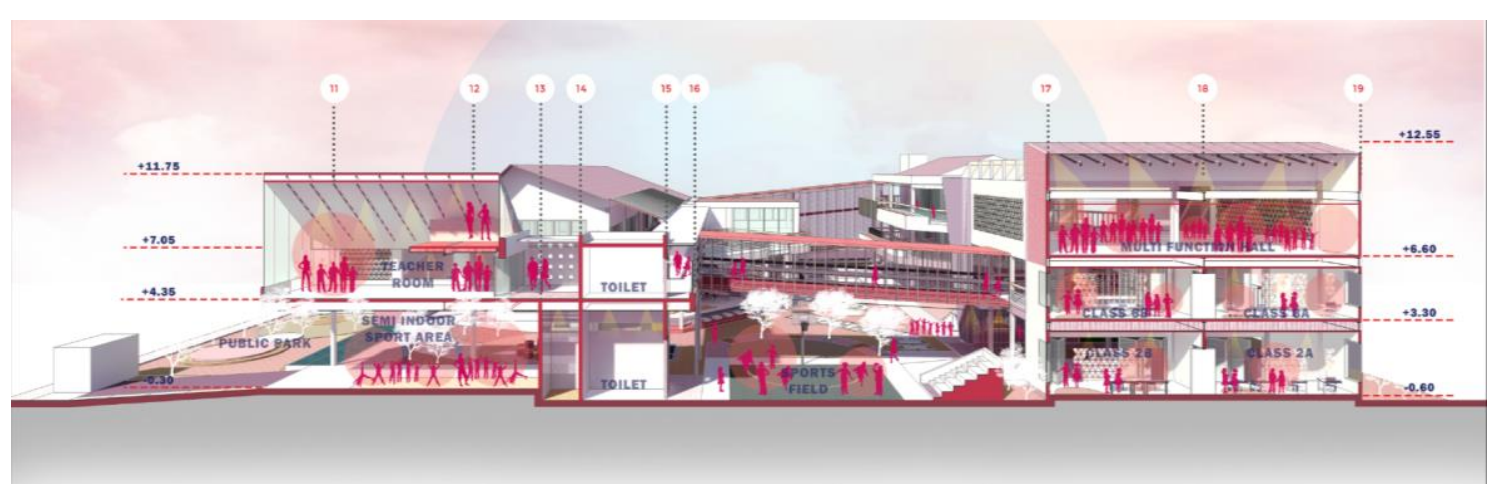

Gambar 3. Potongan Perspektif

Sumber: Penulis, 2019

Secara desain yang membedakan sekolah dasar kontemporer dengan sekolah pada umumnya adalah open space nya lebih tersebar untuk mendukung jalannya aktivitas yang beragam secara bersamaan. Akses yang variatif dan tidak dibatasi untuk menuju satu titik sehingga anak dapat lebih bereksplorasi, serta ruang pembelajaran yang bersifat lebih fleksibel dan multifungsi. Sekolah dasar kontemporer menyediakan pendekatan program pendidikan dasar yang inovatif untuk bermain dan belajar di dalam dan luar ruangan.

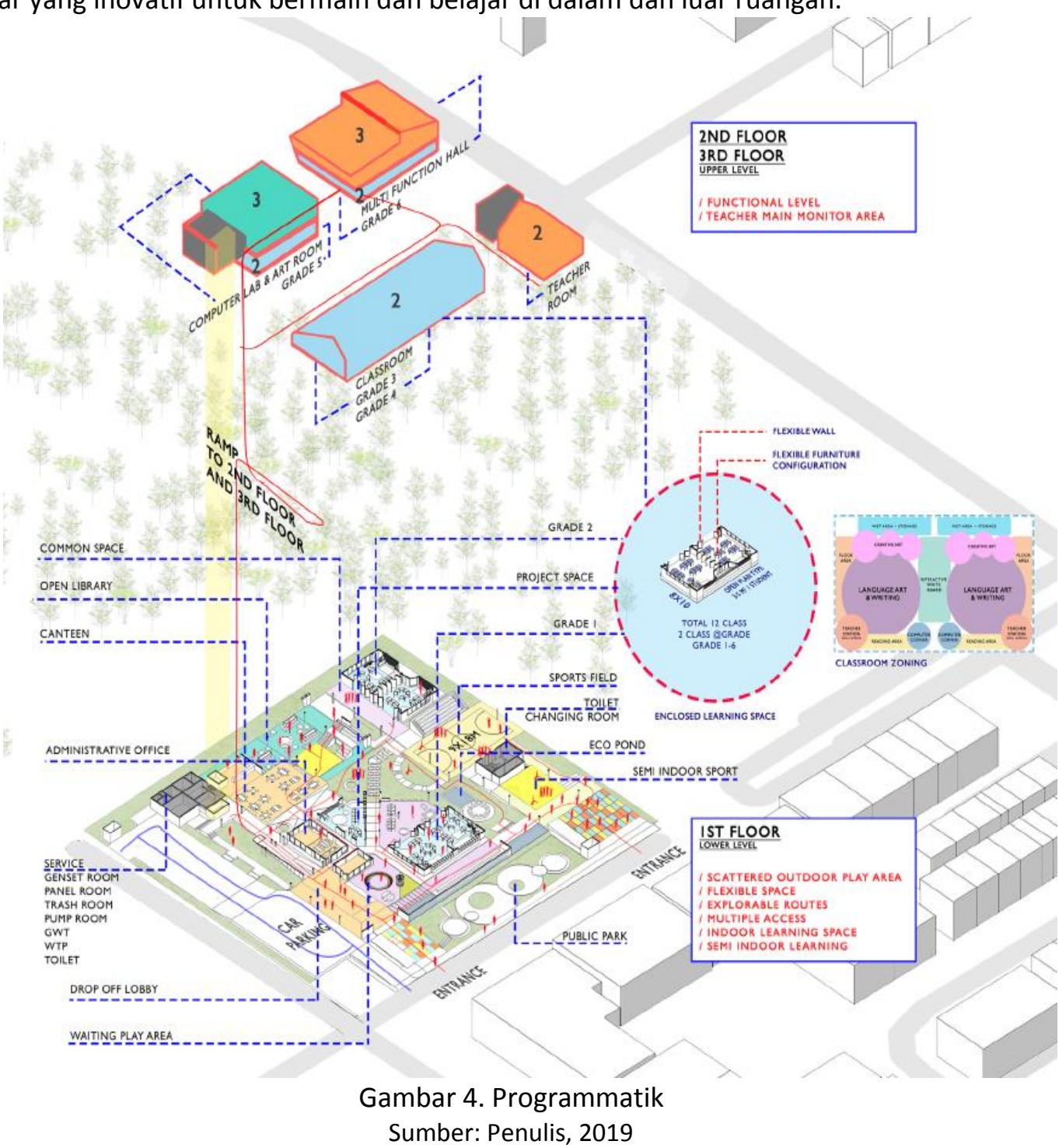




\section{KESIMPULAN DAN SARAN}

Teknologi Informasi dan Komunikasi (TIK) selalu menjadi bagian dari kehidupan generasi milenial, generasi $Z$ dan Alpha. Perilaku belajar dipengaruhi secara mendasar oleh konteks di mana saat itu terjadi. Dalam lingkungan pendidikan terbaru, makna "mengetahui" telah bergeser dari mampu mengingat dan mengulangi informasi menjadi mampu menemukan dan menggunakannya.

Model pembelajaran terbaru dari segi kurikulum, kualitas ruang, konfigurasi ruang, dan program tersebut disesuaikan dengan perilaku mengajar guru milenial dan perilaku belajar murid generasi $Z$ dan Alpha sehingga menghasilkan lingkungan belajar yang kolaboratif antara generasi milenial sebagai tenaga didik dan generasi $z$ dan alpha sebagai peserta didik.

Sekolah kontemporer dengan strategi desain yang memberikan fleksibilitas, konektivitas, dan ruang untuk pertemuan sosial dan pendidikan peserta didiknya. Kurikulum dan program ruang yang menyediakan program pendidikan dasar yang inovatif untuk bermain dan belajar di dalam dan luar ruangan dengan memperhatikan aspek perkembangan fisik, kognitif, emosional dan sosial anak dapat mempersiapkan siswa agar berhasil dalam perkembangan ekonomi pengetahuan.

\section{REFERENSI}

Amalia, R. N. (2011). Sekolah Dasar Bertaraf Internasional. Program Pascasarjana. Universitas Sebelas Maret. Surakarta.

Gandha, M. V. dan Pranata, H. R. (2015). Penerapan Aspek Perkembangan Anak Dalam Perancangan Sekolah Alam Baruna Bahari. Jurnal Kajian Teknologi . 11 (01). Universitas Tarumanagara. Jakarta.

Hertzberger, H. (2007). Space and Learning (Lessons for students in architecture). Rotterdam : 010 Publishers.

Jain, A. (2016). "Don't Teach Me, Let Me Learn! Millennial Learning".

Kuhn, C. (2012). "Typology : Schools". Diterjemahkan oleh : Martha Paramitha. https://www.architectural-review.com/essays/typology/typology-schools/8625738.article/. Diakses tanggal 12 Januari 2019.

Monaco, M. dan Malissa M. (2007). The Millennial Student: A New Generation of Learners. Athletic Training Education Journal. Rocky Mountain University. Provo.

Northern Illinois University. "Millennials : Our Newest Generation In Higher Education". Diterjemahkan oleh Martha Paramitha. https://www.niu.edu/facdev/_pdf/guide/students/millennials_our_newest_generation_in_ higher_education.pdf. Diakses tanggal 9 Januari 2019.

Sweeney, R. (2006). Millennial Behaviors \& Demographics. University Librarian. University Heights. New Jersey.

Vermeulen, E. (2017). What Millennials Demand from Education". Diterjemahkan oleh : Martha Paramitha. https://hackernoon.com/what-millennials-demand-from-educationa291011a71c5/. Diakses tanggal 9 Januari 2019. 
